\title{
Scanning electron microscopy of equine spermatozoa
}

\author{
O. P. Sharma \\ Department of Veterinary Science, University of Kentucky, \\ Lexington, Kentucky 40506, U.S.A.
}

The microscopic examination of semen provides clinically important information. However, this information has been limited by the low resolution of the light microscope. Scanning electron microscopy (SEM) permits observation of free cells and has been used to study the spermatozoa of rabbit (Dott, 1969; Hafez \& Kanagawa, 1973), bull and ram (Dott, 1969), monkey (Hafez \& Kanagawa, 1973), man (Fujita, Miyoshi \& Tokunaga, 1970; Hafez \& Kanagawa, 1973; Martin \& Gould, 1975), and other mammalian species (Zaneveld, Gould, Humphreys \& Williams, 1971). In the present study equine spermatozoa were examined by scanning electron microscopy.

Semen samples were collected from two fertile stallions by means of an artificial vagina. The ejaculate was processed and samples prepared for SEM by the methods of Hafez \& Kanagawa (1973) for observation in a Cambridge Stereoscan (Mark II) at $150 \mu \mathrm{m}$ aperture, operated with an accelerated voltage of $20-25 \mathrm{kV}$.

The preparations were clean and debris was found only occasionally.

The equine spermatozoon is characterized by a flattened ovoid head, covered anteriorly and posteriorly by a smooth surface. The acrosome appeared to cover approximately two-thirds of the anterior part of the head. The sperm head was rounded anteriorly and not so rounded (oval shape) at the posterior end. Distinct marginal thickening of the acrosome along the curved anterior edge, as reported by Dott (1975), was also observed. A narrow line with a serrated appearance extended on each side of the head to the equatorial segment (Pl. 1, Figs 1 and 2). There were considerable variations in the morphology and thickness of the neck. Sometimes the neck appeared as a slight thickening or constriction between the base of the head and the midpiece. Periodic annular constrictions, perhaps related to the underlying mitochondria, were visible in many specimens. The endpiece of the tail was characterized by abrupt narrowing (P1. 1, Fig. 3).

Various types of sperm abnormalities were observed. Deformities of the head were of many types and are illustrated in Plates 1 and 2; they included spheroidal or ellipsoidal shapes and flattened or abnormal acrosomes. Thick, thin or elongated midpieces were also recognized (P1. 1, Figs 4 and 7; PI. 2, Fig. 11). Duplication, which is rarely encountered in the head or the tail, was also seen (P1. 1, Fig. 3) and one spermatozoon with 3 distinct heads, and 3 midpieces covered by the mitochondrial sheath, and with 3 clearly entwined tails was found (PI. 1, Fig. 6).

The present study indicates that SEM is an excellent tool for studying the morphology of spermatozoa. In certain cases of sterility, when morphological examination provides the only means of diagnosis, SEM may be one of the best tools available for diagnosis.

Mr H. Southgate, of the Department of Entomology, University of Kentucky, kindly provided the necessary technical help. This investigation is in connection with a project of the Kentucky Agricultural Experiment Station and is published with the permission of the Director of the Station as publication No. 75-4-76.

\section{References}

Doтt, H.M. (1969) Preliminary examination of bull, ram and rabbit spermatozoa with the stereoscan electron microscope. J. Reprod. Fert. 18, 133-134.

DoTT, H.M. (1975) Morphology of stallion spermatozoa. J. Reprod. Fert., Suppl. 23, 41-46.

Furta, T., Mryoshi, M. \& Tokunaga, J. (1970) Scanning and transmission electron microscopy of human ejaculate spermatozoa with special reference to their abnormal forms. Z. Zellforsch. mikrosk. Anat. 105, 483-497.
Hafez, E.S.E. \& Kanagawa, H. (1973) Scanning electron microscopy of human, monkey and rabbit spermatozoa. Fert. Steril. 24, 776-787.

Martin, D.E. \& Gould, K.G. (1975) Normal and abnormal spermatozoa. J. Reprod. Med. 14, 204-209.

ZANEVELD, L.J.D., Gould, K.G., HuMPhReXS, W.J. \& WiLliams, W.L. (1971) Scanning electron microscopy of mammalian spermatozoa. J. Reprod. Med. 5 , 147-151.

Received 11 May 1976 


\section{EXPLANATION OF PLATES}

\section{PLATE 1}

Figs 1 and 2. Scanning electron micrograph of head and midpiece of normal equine spermatozoa. Note the posterior margin of the acrosome and the annular strictures in the midpiece region and the rigid anterior acrosomal margin (Fig. 2). $\times 3125$.

Fig. 3. A spermatozoon with twin heads. Both heads appear normal in shape and size but the acrosome on the left head is thickened anteriorly. The two midpieces are enwrapped in one membranous structure. The two tails are clearly visible. The structure on the right hand side is the tail and endpiece of a neighbouring spermatozoon. $\times 2000$.

Fig. 4. A spermatozoon with a fractured neck. The equatorial segment marking the posterior boundary of the acrosome is clearly visible. $\times \mathbf{4 0 0 0}$.

Fig. 5. An abnormal spermatozoon with an unusually elongated head. $\times 1580$.

Fig. 6. A spermatozoon with three distinct heads. The three tails are entwined and give the appearance of a single tail. The midpiece region is completely fused. $\times 4100$.

Fig. 7. Abnormal head with deformed acrosome. $\times 1140$.

\section{PLATE 2}

Fig. 8. Equine spermatozoon with deformed head. $\times 4100$.

Fig. 9. Abnormal spermatozoon in which the anterior two-thirds of the head is bent back on the posterior segment. The midpiece is very thin and the attachment of the neck with the head is obscured. $\times 1780$.

Fig. 10. Abnormal spermatozoon. $\times 1200$.

Fig. 11. A spermatozoon with an elongated midpiece with a cytoplasmic droplet. $\times 1100$.

Fig. 12. In this abnormal spermatozoon the anterior tip of the acrosome appears to be 'knobbed'. $\times 2700$. 
1. \II. 1
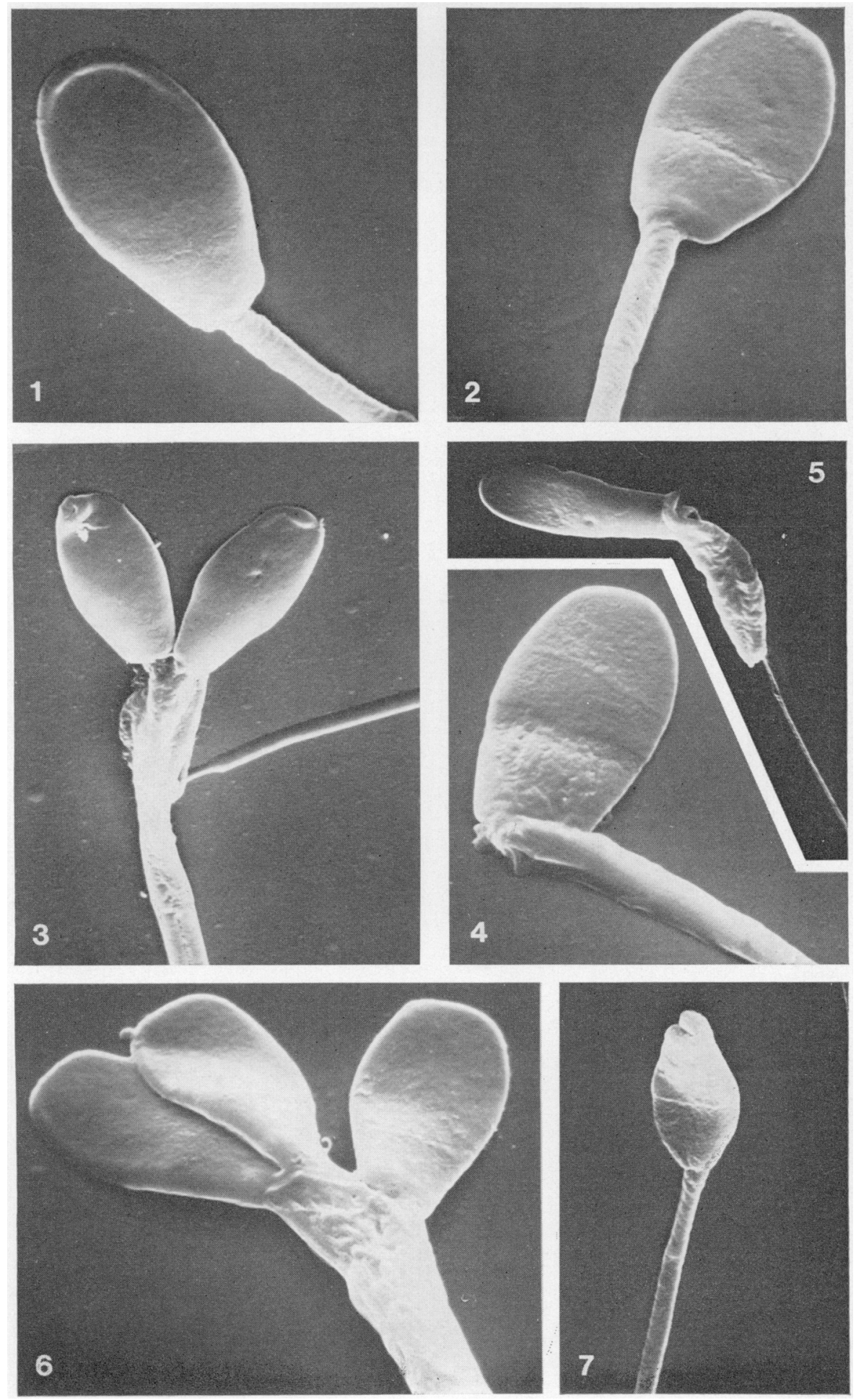
$1: 111 \%$
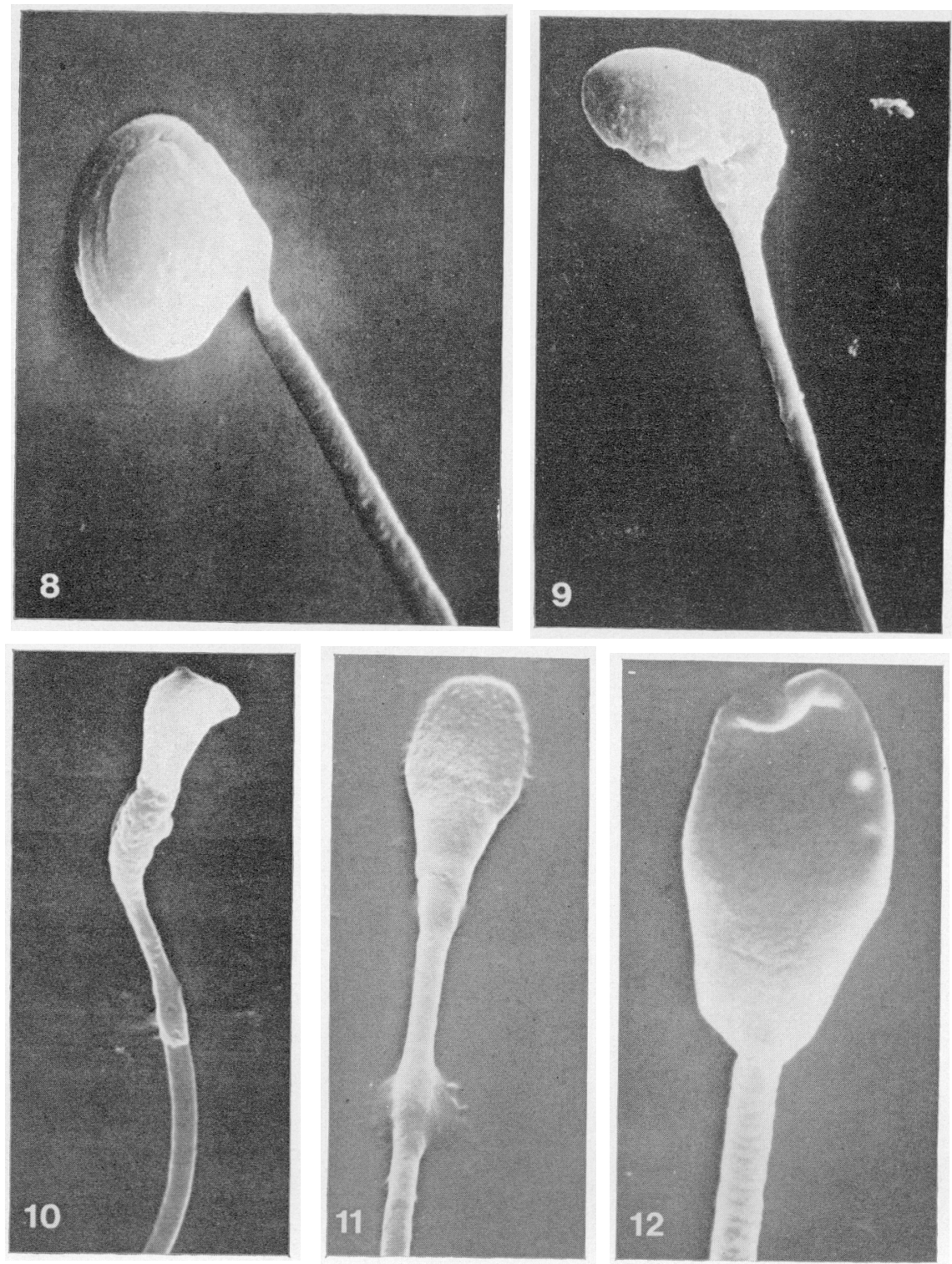